\title{
Chronic physical exercise increases a neurogenesis marker within hippocampus
}

\author{
Mohammad Zulkarnain, ${ }^{1}$ Rostika Flora, ${ }^{1}$ Septi Andrianti ${ }^{2}$ \\ ${ }^{1}$ Department of Public Health, Faculty of Medicine, Universitas Sriwijaya, Palembang, Indonesia \\ ${ }^{2}$ Faculty of Public Health, Universitas Sriwijaya, Palembang, Indonesia \\ 3. Department of Biomedical Science, Faculty of Medicine, Universitas Sriwijaya, Palembang, Indonesia
}

Check for updates

\section{ABSTRACT}

Background: Aerobic and anaerobic physical exercises conducted in both acute and chronic are really essential in keeping the body especially brain healthy. Physical exercise plays an important role in molecular system and is beneficial for the brain by enhancing neurogenesis which is mediated by the increase of BDNF level. This study aimed to evaluate the effect of physical exercise to the BDNF level of hippocampus tissues in Wistar rats.

Methods: Thirty male rats were divided into five groups i.e. control group, acute aerobic physical exercise group, acute anaerobic physical exercise group, chronic aerobic physical exercise group, and chronic anaerobic physical exercise group. Physical exercises were conducted on animal treadmill. The level of hippocampus BDNF was determined using ELISA. The data were analyzed using independent t-test.

Results: BDNF average levels of chronic aerobic and anaerobic physical exercises were higher than those of acute ones $(152.86 \pm 1.62 \mathrm{pg} / \mathrm{ml}$ and $122.22 \pm 1.53 \mathrm{pg} / \mathrm{ml}$ vs $59.38 \pm 6.10 \mathrm{pg} / \mathrm{ml}$ and $54.05 \pm 3.35 \mathrm{pg} / \mathrm{ml})$. There were significant differences in the BDNF average levels of hippocampus tissues between aerobic and anaerobic groups, in both acute and chronic exercise.

Conclusion: The chronic physical exercises, both aerobic or anaerobic, are increasing higher the level of BDNF in brain tissue.

Keywords: acute, aerobic, anaerobic, BDNF, chronic physical exercises

pISSN: 0853-1773• eISSN: 2252-8083• https://doi.org/10.13181/mji.v27i2.1685 • Med J Indones. 2018;27:76-81

- Received 25 Nov 2016• Accepted 14 Dec 2017

Corresponding author: Rostika Flora

rostikaflora@gmail.com

Copyright @ 2018 Authors. This is an open access article distributed under the terms of the Creative Commons Attribution-NonCommercial 4.0 International License (http://creativecommons.org/licenses/by-nc/4.o/), which permits unrestricted non-commercial use, distribution, and reproduction in any medium, provided the original author and source are properly cited. 
Physical exercise is good for heart and cognitive functions. It mediates neurotrophic responses in motor and sensory systems of brain. In addition, physical exercise is also needed to keep cerebrovascular integrity, enhance capillary growth, increase dendritic connections, and improve an efficiency process of central nervous system (CNS). ${ }^{1,2}$

Physical exercise increases the number of new neurons and its ability to survive. The growth of new neurons or the occurrence of neurogenesis process on hippocampus are twice more in routine physical exercises both in acute or chronic. Neurogenesis occuring as the results of physical exercise is accompanied by the increase of brain derived neurotrophic factor (BDNF). The role of BDNF is as a main mediator of synaptic efficacy, a connector of neuron cells, and plasticity of neuron cell. ${ }^{1,3,4} \mathrm{BDNF}$ is active on hippocampus, cortex, and basal forebrain, a vital area for memory, learning, and higher thinking. BDNF is important to keep long-term memory. The highest level of BDNF is found in hippocampus tissues. ${ }^{5,6}$

The result of the study on rats given voluntary trial-running for several days showed the increase of BDNF messenger RNA (mRNA) in hippocampus. Its level increases in several days both in male and female rats, was stable until several weeks during the training and occurs at the same time with the increase of BDNF protein total. This fact shows that BDNF is a good candidate in mediating long-term benefits of exercise in brain. ${ }^{1}$

Many studies have shown positive effects of physical exercise to neurogenesis which is mediated by BDNF and have examined the effects of regular physical exercise on hippocampus BDNF level. However, the studies investigating the effects of aerobic and anaerobic physical exercise conducted in acute and chronic exercise to hippocampus BDNF level are still limited. Therefore, the propose of this research is to compare the level of hippocampus BDNF on aerobic physical exercise and anaerobic physical exercise which is performed in acute and chronic condition.

\section{METHODS}

This study has been approved by a research ethics committee from Faculty of
Medicine, Universitas Sriwijaya No. 075/ kepkrsmhfkunsri/2016, March 24, 2016. This study used laboratory experiment applying posttest control group design conducted in an Animal House of Bio Sains Riset Palembang from April to June 2016. Animal testing used in this study was male Wistar rats, healthy, aged 8-12 weeks, weighed between 100-200 grams, and divided into five groups as follows: 1: control group, given no treatment; 2: treatment group given acute aerobic physical exercise, one-time physical exercise; 3 : treatment group given acute anaerobic physical exercise, one-time physical exercise.; 4: treatment group given chronic aerobic physical exercise for five days per week, for four weeks; 5 : treatment group given chronic anaerobic physical exercise for five days per week, for four weeks. Each group consisted of six rats. Thus, the total number of sample needed for five groups was thirty rats.

Acute physical exercise was a physical exercise performed once per week for 4 weeks, while chronic physical exercise was performed daily ( 7 times per week) for 4 weeks. Anaerobic physical exercise was given by placing the animal testing into animal treadmill and set the treadmill in the speed of $35 \mathrm{~m} / \mathrm{min}$ for 20 minutes. An interval was given in each 4 minutes in the speed of $20 \mathrm{~m} / \mathrm{min}$ for 1 minute. On the other hand, aerobic physical exercise was given by placing the animal testing into an animal treadmill and run it in the speed of $20 \mathrm{~m} / \mathrm{min}$ for 30 minutes continually. ${ }^{7}$

Acclimatization of animal testing was performed in one week by putting them into animal treadmill and run it in the speed of 5-10 $\mathrm{m} / \mathrm{min}$. Before and after the treatments, the body weight and rectal temperature of animal were measured. The treatments were conducted for four weeks. On the last day of the study, the animal testing was decapitated soon after the rats ran on treadmill.

\section{Preparation of brain tissue homogenate}

The brain of rat taken from surgery was put on a glass slide. Some gel ices were placed right under the glass slide to keep the brain fresh. The parts of brain were separated, and the hippocampus tissues were taken out. The hippocampus tissues were weighed and were put into a microtube $1.5 \mathrm{ml}$. By using a micropippette, 
1,000 microlite of phosphate buffered saline (PBS) $0.01 \mathrm{M}$ (pH 7.4) was transferred into a microtube containing hippocampus. The tissues were crushed using homogenizer for \pm 1 minute at 8,000 rpm. Moreover, the tissues were centrifuged for 5 minutes at 8,000 rpm. Then, the supernatant was taken out and separated into a new microtube.

\section{Determination of BDNF level}

Hippocampus BDNF level was determined by enzyme-linked immunosorbent assay (ELISA) method using Rat BDNF ELISA Kit from Elabscience. The level of BDNF was obtained from standard curve by preparing BDNF standards in different concentrations from $500 \mathrm{pg} / \mathrm{ml}, 250 \mathrm{pg} /$ $\mathrm{ml}, 125 \mathrm{pg} / \mathrm{ml}, 62.5 \mathrm{pg} / \mathrm{ml}, 31.25 \mathrm{pg} / \mathrm{ml}, 15.63 \mathrm{pg} /$ $\mathrm{ml}, 7.81 \mathrm{pg} / \mathrm{ml}$, and $0 \mathrm{pg} / \mathrm{ml}$. This curve formed a linear relationship between absorbance at $450 \mathrm{~nm}$ and different concentrations of BDNF. Based on the linear curve, the equation of $\mathrm{Y}=\mathrm{ax}+\mathrm{b}$ was obtained. This equation shows that in the concentrate area of BDNF which used for standard, absorption on the $4,450 \mathrm{~nm}$ wavelength is directly proportional. From these equation, the concentrate of hippocampus BDNF tissues was calculated.

\section{Data analysis}

The data of the study were analyzed using statistical package for the social sciences (SPSS) for Windows version 19. The level of significance was set at $<0.05$. Independent t-test was used to find out the mean difference among the groups of population.

\section{RESULTS}

Body weight (BW) and body temperature were measured before and after physical exercise. The characteristics of research subject in term of body weight and body temperature are displayed in Figure 1 and Figure 2. It can be seen from Figure 1 that the body weight of animal testing in the control group was increased. On the other hand, the body weight of rats in treatment groups with acute or chronic physical exercises was decreased. Figure 2 shows that the body temperature in all treatment groups was increased after given physical exercises.

\section{Hippocampus-tissue BDNF levels}

Based on the measurements of average

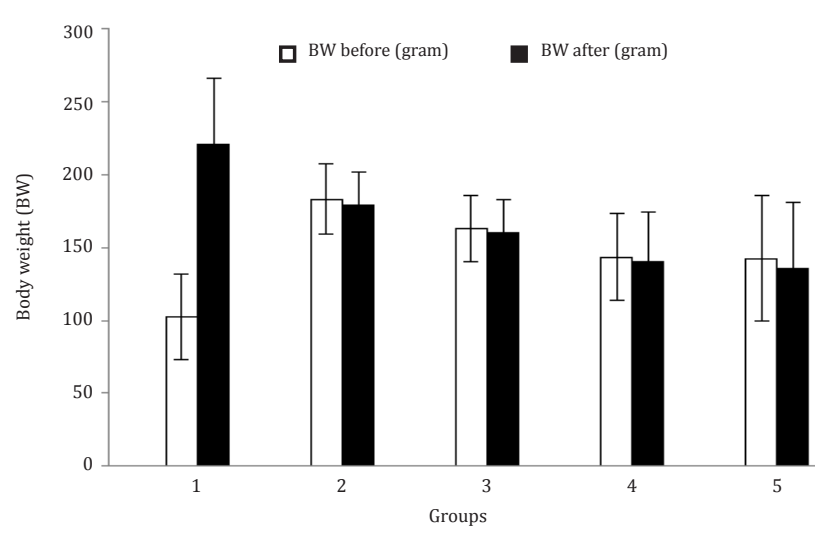

Figure 1. The characteristics of the animal based on body weight. Body weight measurements were performed before and after the physical exercise. The weight loss after the physical exercise $(\Delta \mathrm{BW})$ shows a dehydration after they performed physical exercise 1: control group; 2: acute anaerobic physical exercise group; 3: acute aerobic physical excercise group; 4: chronic anaerobic physical exercise group; 5: chronic aerobic physical exercise group

level of hippocampus BDNF, an increase of a hippocampus BDNF level in the treatment groups was found. The average levels of hippocampus BDNF in aerobic physical exercises groups in both acute and chronic were higher than those in anaerobic and the control group.

\section{DISCUSSION}

Based on the results of the study, the average level of BDNF in all treatment groups was increased compared to the control group. The increased level of BDNF might be caused by the physical stress happening during the exercises. Physical exercise can cause physical stress if it is done for the first time (acute) and if it is done continuously (chronic). ${ }^{8}$

Either acute or chronic stress can influence the synthesis of BDNF in brain. When chronic stress occurs, hypothalamic-pituitaryadrenocortical (HPA) system is activated. HPA system plays a role in immunology system and neuron plasticity that influence cell survival. Chronic physical exercise generates stress that lasts for long. This long lasting stress has an impact on atrophy on gyrus dentatus and cornu ammonis 3 (CA3) region of hippocampus causing decreased memory functions. To avoid decreased memory function, a large amount of BDNF is produced. ${ }^{9-11}$ 


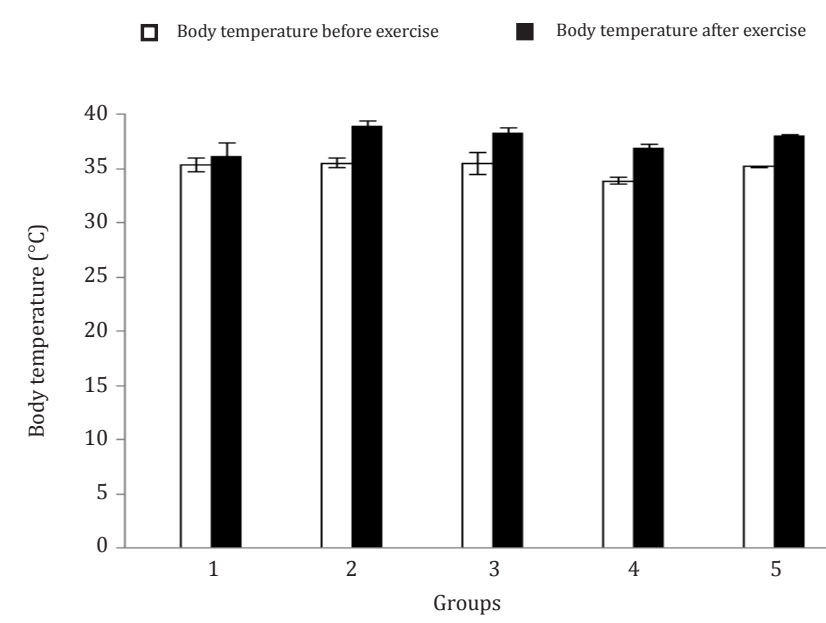

Figure 2. The characteristics of the research subjects that are based on body temperature. The body temperature can be known by measuring the anal temperature before and after physical exercise. The differences in body temperature before and after the subjects performed physical exercise $(\Delta \mathrm{T})$ show the metabolism were increasing during physical exercise. The increased body temperature of treatment group was higher than the control group

The increase of BDNF level in acute physical exercise is caused by physical stress, then corticotropin-releasing hormone (CRH) (fast receptor) is released through $\mathrm{CRH}-1$ receptor (CRHR1). It will stimulate HPA axis which later on produces mineralocorticoid. Acute stress modulates receptor type I i.e. mineralocorticoid receptor (MR) located in hippocampus. This modulation influences hippocampus in terms of learning process and memory. MR will stimulate long-term potentiation (LTP), so that neurite outgrowth is increased. The increase of neurite outgrowth is followed by the increase of BDNF.

This study showed that there was a significant difference in the level of hippocampus BDNF of Wistar rat brain tissues in the treatment groups in both acute and chronic compared with the control group. Physical exercise can induce a production of growth factor such as BDNF which is needed in neurogenesis and has an impact to cognitive functions. In addition, physical exercise can create responses to BDNF, neurogenesis, and cognitive functions through insulin-like growth factor 1 (IGF-1). Aside from these, there are some other factors influencing physical exercise and playing a role in cognitive functions. Physical exercise through BDNF causes hypertrophy hippocampus which later on will have preventive function in neuronal degeneration. ${ }^{12}$
The results of this study also revealed that there was a significant difference in the level of hippocampus BDNF of Wistar rat brain tissue in the treatment groups between chronic anaerobic and chronic aerobic. Anaerobic physical exercise is physical exercise that takes energy from anaerobic metabolism or does not depend on oxygen availability (anaerobic) and produces numerous lactic acids as final products. When doing anaerobic physical exercise, the level of blood lactic acid will be elevated, thus lactic acid will get into the brain and bind to a receptor of G protein-coupled receptor 81 (GPR81) or a hydroxycarboxylic acid receptor 1 (HCAR1) in vascular and brain cells. Furthermore, it will regulate cyclic adenosine monophosphate (cAMP) level since excessive cAMP can lower cognitive functions. Previous studies have stated that lactic acid in blood can lower the level of blood BDNF. During the physical exercise, BDNF is regulated through mitogen-activated protein kinase (MAPK) and $\mathrm{Ca}^{2+} /$ calmodulin-dependent protein kinase II (CaMKII) pathways. These pathways are important in synaptic process. Mitogen-activated protein kinase/extracelullar-signal-regulated kinase (MAPK/ERK) is involved in synaptic plasticity and memory and several extracellular signals. Protein kinase $\mathrm{C}$ delta $(\mathrm{PKC}-\delta$ ) is needed to activate MAPK to grow neurons, and CaMKII is needed to influence $\mathrm{Ca}^{2+}$. ${ }^{12-15}$

Acute physical exercise increases the level of plasma BDNF (pBDNF). One session of physical exercise can increase the level of pBDNF in accordance with the intensity of physical exercise. The increase of serum pBDNF depends on the intensity of physical exercise. Chronic physical exercise is proved to increase BDNF mRNA in hippocampus. Meanwhile, in acute physical exercise, the increase of BDNF concentrations is seen in the periphery organ. Both acute and chronic physical exercise cause BDNF level increased in various regions of brain. BDNF significantly increases, and it is correlated with the intensity of physical exercise. ${ }^{15-17}$

The activity of lymphocyte $\mathrm{T}$ on glial cells influence the secretion of BDNF in neurons in CNS. However, stress can inhibit lymphocyte $\mathrm{T}$ activity, thus will inhibit the secretion of BDNF. Chronic stress can disturb a cognitive functions i.e. learning ability and memory. Besides, morphological destruction occurs in nervous systems as the results of chronic 


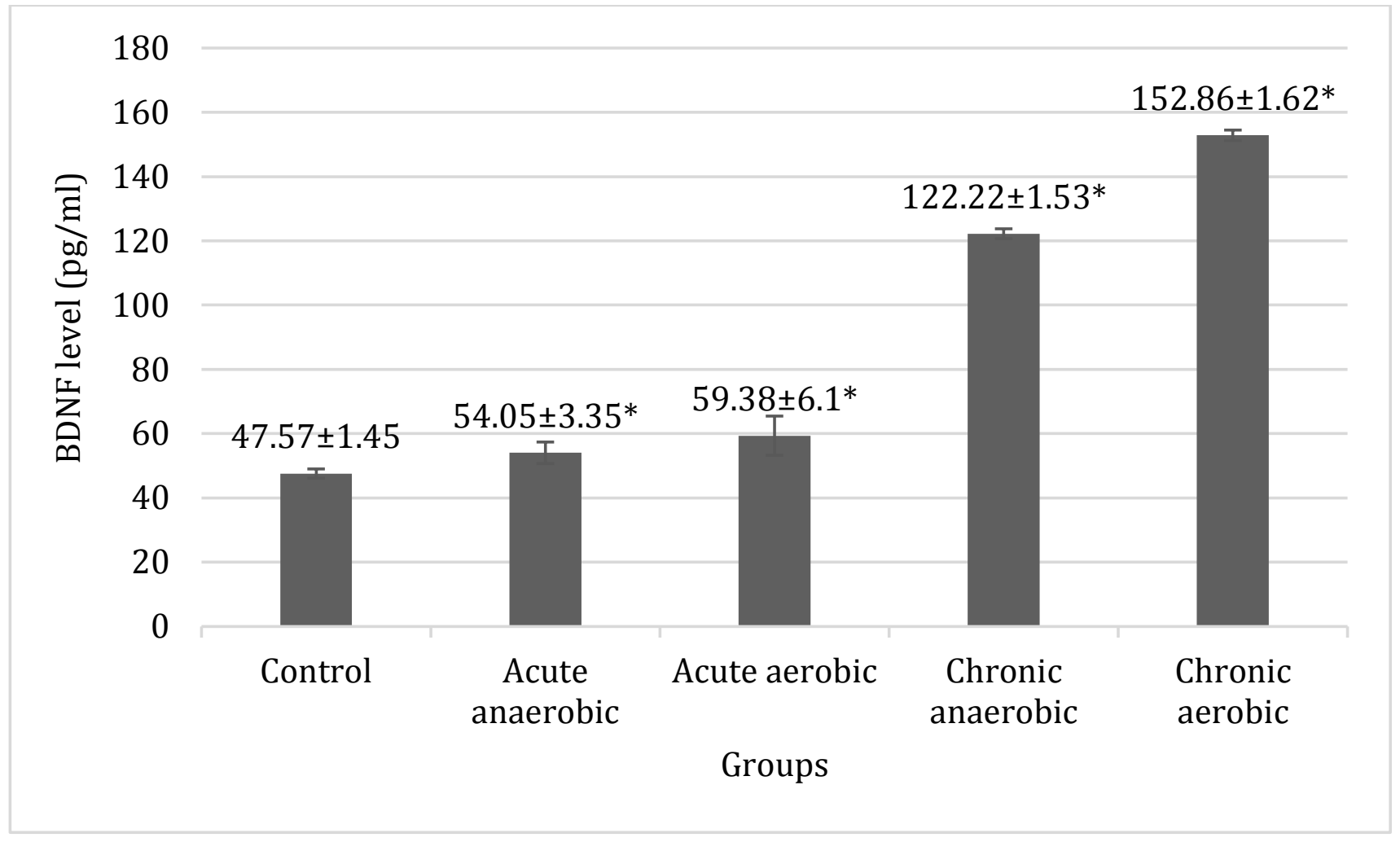

Figure 3. Comparison of hippocampus BDNF level of Wistar rat brain tissues between the control and the experimental groups. There was a significant difference $(* \mathrm{p}<0.05)$ of BDNF levels of brain tissue at all treatment groups were compared with the control group, and between acute and chronic physical exercise

stress such as apical dendritic atrophy CA3 and the decrease in both proliferation and neurogenesis on gyrus dentatus of hippocampus. ${ }^{18,19}$

Physical exercise can influence the motor memory ability and motor skills. The study on rats given voluntary trial-running for several days showed the increase of BDNF mRNA in hippocampus. This increase was occured in several days and the level was stable until several weeks during the training. The increase of BDNF mRNA occured at the same time with the increase of BDNF protein total. This fact shows that BDNF is a good candidate in mediating long-term benefits of exercise in brain. ${ }^{4,20,21}$ It shows that in the field of clinical, exercise may play a role in overcoming cognitive impairment in people with depression as well as the elderly.

A limitation to this research is that the measurement of BDNF level is only performed one time, right after the physical training. Thus, it is unknown when the BDNF level are increasing to its peak. However, the result of this can be used as the basic of policy in establishing physical exercise as non-pharmacological therapy to improve the brain health.

In conclusion, the chronic physical exercises, both aerobic or anaerobic, increased the level of BDNF in brain tissue higher than control and acute physical exercises group.

\section{Conflict of interest}

The authors affirm no conflicts of interest in this study.

\section{Acknowledgment}

The researcher are grateful to government for the support to this study through a grant 'Hibah Pascasarjana Kemenristekdikti 2016'.

\section{REFERENCES}

1. Erickson KI, Voss MW, Prakash RS, Basak C, Szabo A, Chaddock L, et al. Exercise training increases size of hippocampus and improves memory. Proc Natl Acad Sci USA. 2011;108(7):3017-22.

2. Thomas AG, Dennis A, Bandettini PA, Johansen-Berg H. The effect of aerobic activity on brain structure. Front 
Psychol. 2012;86(3):1-9.

3. Van Essen DC, Dierker DL. Surface-based and probabilistic atlases of primate cerebral cortex. Neuron. 2007;56(2):209-25.

4. Cotman CW, Berchtold NC. Exercise: a behavioral intervention to enhance brain health and plasticity. Trends Neurosci. 2002;25(6):295-301.

5. Bekinschtein P, Oomen CA, Saksida LM, Bussey TJ. Effect of environmental enrichment and voluntary exercise on neurogenesis, learning and memory, and pattern separation BDNF as a critical variable. Semin Cell Dev Biol. 2011;22(5):536-42.

6. Mandel AL, Ozdener H, Utermohlen V. Identification of pro- and mature brain-derived neurotrophic factor in human saliva. Arch Oral Biol. 2009;54(7):689-95.

7. Flora R, Zulkarnain M, Sorena E, Deva ID, Widowati W. Correlation between hypoxia inducible factor- $1 \alpha$ and vesicular endothelial growth factor in male wistar rat brain tissue after anaerobic exercise. Trends Med Res. 2016;11(1): 35-41.

8. McArdle, WD, Katch, PI, and Katch, VI. Essential of exercise physiology. Philadelphia: Lea and Febiger. 2014

9. Suh H, Deng W, Gage FH. Signaling in adult neurogenesis. Annu Rev Cell Dev Biol. 2009;(25):253-75.

10. Hendrickson ML, Rao AJ, Demerdash ON, Kalil RE. Expression of nestin by neural cells in the adult rat and human brain. PLoS One. 2011;6(4):e18535.

11. Lupien SJ, Lepage M. Stress, memory, and the hippocampus: can't live with it, can't live without it. Behav Brain Res. 2001;127(1-2):137-58.

12. Foster PP, Rosenblatt KP, Kuljiš RO. Exercise-induced cognitive plasticity, implications for mild cognitive impairment and Alzheimer's disease. Front Neurol. 2011;28(2):1-15.
13. Bergesren LH. Lactate transport and signaling in the brain: potential therapeutic targets and roles in body-brain interaction. J Cereb Blood Flow Metab. 2015;35(2):176-85.

14. Halestrap AP. The SLC16 gene family - structure, role and regulation in health and disease. Mol Aspects Med. 2013;34(2-3):337-49.

15. Molteni R, Ying Z, Gómez-Pinilla F. Differential effects of acute and chronic exercise on plasticity-related genes in the rat hippocampus revealed by microarray. Eur J Neurosci. 2002.16(6):107-16.

16. Piepmeier AT, Etnier JL. Brain-derived neurotrophic factor (BDNF) as a potential mechanism of the effects of acute exercise on cognitive performance. J Sport Health Sci. 2015;4(1):14-23.

17. Ferris LT, Williams JS, Shen CL. The effect of acute exercise on serum brain-derived neurothropic factor levels and cognitive function. Med Sci Sports Exerc. 2007;39(4):728-34.

18. Sleiman FS, Henry J,Al-Haddad R, ElHayek L, Abou Haidar E, Stringer T, et al. Exercise promotes the expression of brain derived neurotrophic factor (BDNF) through the action of the ketone body $\beta$-hydroxybutyrate. eLife. 2016;5:e15092.

19. Schwartz N, Schohl A, Ruthazer ES. Neural activity regulates synaptic properties and dendritic structure in vivo through calcineurin/NFAT signaling. Neuron. 2009;62(5):655-69.

20. Vaynman S, Ying Z, Gomez-Pinilla F. Hippocampal BDNF mediates the efficacy of exercise on synaptic plasticity and cognition. Eur J Neurosci. 2004;20(10):2580-90.

21. Roig M, Skriver K, Lundbye-Jensen J, Kiens B, Nielsen JB. A single bout of exercise improves motor memory. PLoS One. 2012;7(9):e44594. 